\title{
Guiding the Herd: The Effect of Reference Groups in Crowdfunding Decision Making
}

\author{
Yu Lei \\ SUNY College at Old Westbury \\ leiy@oldwestbury.edu
}

\author{
Ali Alper Yayla \\ Binghamton University - SUNY \\ ayayla@binghamton.eud
}

\author{
Surinder Singh Kahai \\ Binghamton University - SUNY \\ kahai@binghamton.edu
}

\begin{abstract}
Despite their popularity, crowdfunding platforms are experiencing negative headlines as fully funded projects continue to fail delivering the products on time. Current literature postulates that funders make decisions by following the decisions of the crowd, and this herd behavior leads to less than optimal decisions. One explanation of the negative externalities of such behavior is the misfit between the information provided by the crowd and the information needed by funders. Especially in patronage crowdfunding, funders are investors and buyers at the same time. This duality coupled with the lack of supervision of projects creates unique challenges. In addition to opportunism uncertainty, funders face competence uncertainty. This study provides evidence that social information gathered from reference groups decrease these uncertainties. Further investigation showed that different reference groups provide different types of social information and product complexity plays a role in the uncertainties experienced and the importance given to different reference groups.
\end{abstract}

\section{Introduction}

The notion underlying crowdfunding is clear: attaining access to the public to seek funding, generally for small ventures which are unlikely to get funding through traditional sources such as venture capital. The power of crowdfunding is substantial. By early 2016, 2.2 billion dollars were pledged on KickStarter, which is considered as one of the largest crowdfunding websites in the US [31]. However, despite its popularity among grassroots entrepreneurs, crowdfunding is not without challenges. For instance, only $33 \%$ of the projects on Kickstarter are successfully funded [31][1], and most of the projects raise less than $\$ 10,000$ [11]. Furthermore, some of the successfully funded projects were even cancelled due to project initiators' fraudulent promise of or over- confidence about the final product's quality and features [54].

The vast number of projects and limited demonstrability of the innovative products in these projects are potential reasons for unsuccessful projects on crowdfunding platforms. These issues create information overload and ambiguity among funders, which consequently lead to herd behavior [55]. That is, to differentiate good projects from less desirable ones, funders resort to following other people's decisions, assuming that others have more information about the project [56]. Using reference groups to form purchase decisions is prevalent in online shopping, especially when consumers have limited experience with products. Although herding is not always irrational [56], it may incur negative externalities [3], especially in crowdfunding [15].

While funders can follow different reference groups like crowd, friends, or experts, it is not clear which reference group they will choose to aid their decision making process. Past studies have focused primarily on one particular reference group influence - peer [7] or experts [42] - and have not examined differences across reference groups. Additionally, past studies have not systematically examined the mechanism that drives herd behavior in crowdfunding. They have attributed herd behaviors to uncertainty as a result of funders' limited experience or information to evaluate projects [48], without explicitly examining what may affect this uncertainty.

In this study, we attempt to address these research gaps in the crowdfunding literature. Based on social comparison theory [6] and rational choice theory [29], we propose that there are two types of seller related uncertainty faced by a funder: seller opportunism uncertainty (SOP) and seller competence uncertainty (SCP). Furthermore, we argue that different reference groups (crowd/friends/experts) provide different types of information (explicit vs. implicit) that funders can utilize to reduce these distinct uncertainties. After distinguishing the types of uncertainty and effects of different reference groups, we examine when and why funders follow one specific reference group over the 
others. More formally, we examine the following: 1) what is the distinctive informational influence that each reference group exerts on funders? 2) how do two types of uncertainty (i.e. SCP and SOP) relate when funders face different types of products? 3) under what conditions funders follow a particular group (crowd/friends/experts) over the others?

This study differs from the growing body of crowdfunding studies in following ways. First, to our knowledge, our study is the first to distinguish the effects of various reference groups by investigating different types of social information each group provides (explicit/implicit) during funders' decision making process. Second, this study differs from existing studies of recommendation systems and reference groups in e-commerce context, since in patronage crowdfunding (e.g., Kickstarter) funders are also buyers of the products that are yet to be developed by new entrepreneurs, limiting the ability to judge the products and project initiators/sellers. Thus in addition to opportunism uncertainty, related to seller's honesty, funders face competence uncertainty, related to seller's ability to produce the product. Finally, we provide evidence that funders choose reference groups based on product complexity, which influences the types of uncertainty they face during decision making. The proposed fit between the type of seller uncertainty and social information gives further insights into the unique challenges of crowdfunding websites. Our findings have practical implications as well. Since the main revenue source of crowdfunding websites is the fee they collect from the raised funds, by reducing the information uncertainty funders face and enabling them to make more informed decisions, these websites will likely have more successful funders and less failed projects.

\section{Literature review}

One research stream in the crowdfunding literature focuses on the project level and examines factors that influence projects' successful funding, nature of projects, and the impact of project-crowd fit [7][52]. Another research stream concentrates on factors that influence funders' decision process and contribution patterns such as funders' cultural and geographic differences [1][17][45], desire for social interactions with those who are involved in to the project [33] and funders' altruism [16]. The majority of the studies in the latter research stream focus on herd behavior.

Among various types of crowdfunding platforms, [28], patronage crowdfunding has a considerably different dynamic among project initiators and funders. While funders do not expect economic return in philanthropic funding, they expect economically rational return in lending and equity funding by bearing certain investment risks. In patronage funding, on the other hand, funders are not only investors of projects but also buyers of the to-be-finished product. This feature creates unique challenges which arise due to high level uncertainty as a result of lack of due diligence of project initiators, lack of supervision after project is fully funded, lack of consumer protection if the project fails, lack of quality control of products since they are yet to be produced, and lack of information on project initiators since they are mostly first time or local entrepreneurs.

In summary, patronage crowdfunding enables funders to buy an unfinished product, by investing in someone who, most likely, is a first time entrepreneur that funders don't necessarily have close ties with. Since these entrepreneurs are both the creators of their projects and also sellers of the final product, funders have to evaluate two different facets of uncertainty at the same time - whether the project initiator is 1) faithful or trustworthy and 2) competent to finish and deliver a high quality product. This complexity and high level of uncertainty funders face lead them to one of the few available information sources to make their decision - the crowd. That is, when funders lack the resources to decide on their own if a particular project is worth investing and, at the same time, the project initiator is not only trustworthy but also capable of finishing this project, they follow the crowd's decision. Several studies have found support for this herd behavior [9][12][36][44]. However, further evidence shows that this herd behavior leads to negative externalities in the form of suboptimal decisions [16][56]. Risky or bad projects are still funded since funders make decisions not based on the characteristics of the project or its initiator but based on the number of people who have invested before them. That is, funders are likely to be attracted to projects which already accumulate prior investors [20]. However, a significant portion of these early investors are likely to be project initiator's friends or family members [38], who may have pledged money as a goodwill gesture to support the venture rather than profiting from the investment [2]. In such cases, the number of prior investors does not necessarily signal the true quality of the project or its initiator. For instance, the "iFind" project on Kickstarter raised more than half a million dollars within weeks but cancelled when some funders who had relevant expertise started to question the viability of the project. If funders had access to the professional opinion at the 
time of their decision, they might have chosen not to pledge instead of following the crowd and simply "believing" that other funders had relevant knowledge.

\section{Theoretical gap in current crowdfunding research}

We submit that the current state of the crowdfunding research provides an incomplete understanding of the decision process of funders, especially in patronage crowdfunding, for two main reasons. First, most studies that reported the existence of herd behavior investigated crowdfunding types that are economically rational (lending or equity). While the need for herd behavior may be the same (uncertainty due to limited information), the underlying assumptions may not hold true in patronage funding. For instance, in prosper.com, funders can earn more interest from high risk borrowers - a common high risk/high return scenario. However, in patronage funding, while the level of uncertainty may vary across projects, the maximum reward is generally constant - buying the product at a discounted price. Since funders are also consumers of the product, the decision cannot solely depend on the discount amount. Moreover, in most cases, the reward systems in patronage crowdfunding do not have an economically rational return. For instance, individuals may be rewarded with a simple thank you card for their $\$ 5$ investment. Thus, it is not correct to treat decision makers in patronage funding only as homo economicus and expect that their decisions or desires are economically rational. When decision making lacks the economic motivation, social information becomes an important external source of information [41].

Second, the lack of an appropriate supervisory system in patronage funding may lead to information asymmetry and agent-principal problem between project initiators and funders [5]. In reality, the crowd cannot truly assess project initiators' competence or opportunism. Moreover, the crowd may include those who can assess the competence of the project initiator (e.g., experts from the same industry), or who can assess the opportunism of the project initiators (e.g., friends of the project initiator), or who can assess both/neither. Therefore, crowd's behavior provides mixed signals at best. This is potentially one of the reasons of negative externalities of the herd behavior in patronage crowdfunding platforms. Overall, we argue that the information signaled by the choices of the crowd is not adequate to mitigate unique challenges of patronage funding. Better decision making can be achieved by providing different types of social information from variety of reference groups compared to the mixed signals of the crowd.

The main thesis of our paper is in certain conditions (e.g., high product complexity) the need for expertise based information becomes more salient whereas in other conditions (e.g., low product complexity) the need for trust based information is more salient. The fit between the type of information decision makers need and the type of information reference groups provide would result in better decision outcomes compared to following solely the crowd, which provides mixed information.

\section{Theory and hypothesis development}

Rational choice theory postulates that rational individuals consider and compute the outcomes of alternative choices and choose the one they believe is best for their own benefits, which can be maximization of their utility function or attainment of their greatest personal advantage [35][53]. In most circumstances, however, individuals are unlikely to have all the necessary information to make a rational decision, which forces them to make choices not only about their goals but also the corresponding means to achieve these goals. Therefore, the information individuals possess becomes a key factor that influences their final decisions [53]. When they lack the necessary information, individuals seek additional sources of information to cope with existing uncertainties [47]. One available source is the behaviors of previous decision makers. When decision making becomes costly as a result of search, analysis, and evaluation of alternatives, individuals tend to lean towards irrational decision making modes such as imitation, habit, hunch, experimentation, impulse, or obedience [21]. Thus, irrational decision making imitation - occurs to economize the decision-making process. In other words, individuals aim to make the right choice by minimizing the decision costs rather than optimizing the decision outcome, which can be accomplished by following others' decisions. Although this herd behavior is believed to be fragile, and possibly leading to fads, it does not always lead to irrational outcomes, because in some cases the private information that individuals depend on to make decisions is not sufficient.

One important information source that decision makers can use is reference groups that serve as anchors to relate or compare to. Reference groups are psychologically significant for decision makers and therefore affect their behavior [4]. Social comparison 
theory postulates that people make decisions based on how they associate themselves with socially comparable others or with their "aspirational group" so that they can make similar decisions [26][29]. Reference groups can provide social information that influences individuals by affecting how they perceive a product (informational influence), their values (value-expressive influence), or their behaviors (utilitarian influence) [49]. Within the context of our study, informational influence plays an important role in funders' decision-making process because the social information is internalized and is used either to enhance individuals' knowledge or improve their ability to cope with certain aspects of the environment. The more credible the information is, the more likely it is to be internalized, and therefore, making the source of information critical [49]. Previous research has shown that the crowd can be utilized as a reference group. However, the nature of the social information it carries is mixed because the people's identities are not verified in the large social network. Based on a recent study, experts exist among crowds, and despite their comparatively small numbers, their professional expertise cannot be easily replaced by large crowds [34]. According to Burt [14], people who reside in an intimate social network share thick trust with each other, which implies that friends are more reliable and trustworthy compared to the crowd. Similarly, for experts, despite being in a distant network, they signal more professional knowledge compared to the crowd.

\subsection{The effect of reference groups on seller uncertainty}

Funders on crowdfunding sites are usually confronted with various types and levels of uncertainty. We can group these uncertainties into three types: funding uncertainty, seller (i.e. project initiator) uncertainty, and product uncertainty. In this study we investigated seller uncertainty, which is also an important determinant of product uncertainty. In ecommerce, seller uncertainty is caused by buyers' incapability to evaluate sellers due to sellers' misrepresentation and opportunism, which are both related to sellers' honesty [23][50]. In crowdfunding, seller uncertainty also exists and greatly affects product's quality and project's success. However, it is displayed differently from e-commerce platforms. On patronage crowdfunding platforms most project initiators are first time entrepreneurs or less known local or amateur artists with products yet to be produced. Therefore, funders are concerned about project initiator's ability to successfully produce the product. This uncertainty is not due to seller's dishonesty but rather it is due to seller's competence. Thus, in addition to seller's opportunism uncertainty funders also face this unique seller uncertainty related to seller's competence in patronage crowdfunding.

Moreover, in crowdfunding environment, funders have limited access to the necessary information they need to make rational choices. The available information is generally provided by project initiators in the form of words, graphs, or videos. Lack of naturalness of information communicated through the Internet may create ambiguity [43] and increase the difficulty of making decisions [47]. Under such circumstances, decision makers usually employ other strategies to reduce the uncertainty level [47], such as collecting additional information [22], deferring decisions until necessary information is available [37], or assumption-based reasoning when additional information is not attainable [19].

Individuals can also depend on external references to justify their decisions and choose the best alternative under high uncertainty resulting from constrained media naturalness and lack of personal experience [25]. As discussed earlier, this behavior leads to social rationality [46], where individuals abandon their own preferences and simply mimic others' behaviors even though it can lead to suboptimal decisions [10]. When individuals follow reference groups, they internalize the social influence attained from the decisions of the reference group and in turn this internalization increases their knowledge about certain aspects of the environment [4]. Based on this rationale, we argue that funders in crowdfunding websites will follow the decisions of reference groups as a common heuristic to deal with the existing uncertainty. The extant crowdfunding literature provides limited support as the studies show herd behavior as funders follow the crowd's decision [16][36][56]. However, we argue that similar rationale will hold true for other reference groups (experts/friends), and funders will behave similarly, and follow them to reduce seller uncertainty. Thus, we hypothesize,

Hla: Social information from reference groups will reduce seller competence uncertainty.

H1b: Social information from reference groups will reduce seller opportunism uncertainty.

\subsection{Product complexity and seller uncertainty}

Distinct features of competence uncertainty and opportunism uncertainty suggest that funders 
experience different types of uncertainty. While funders face both types simultaneously, the magnitudes of the uncertainties are likely to vary with product complexity. For projects perceived to be less complex, funders are likely to have a good understanding of the product and manufacturing process. In these situations, funders' main concern is not likely to be the sellers' capability but the sellers' potential opportunistic behaviors. For instance, if the crowdfunded project is a photo album by a photographer, the perceived product complexity would be low and whether the album is finished is more likely dependent on the photographer's intentions (e.g., will she do the photo album?) rather than her capabilities (e.g., can she take the photos and make a book out of them?). Thus, we postulate that:

H2a: When product complexity is low, seller opportunism uncertainty will be greater than seller competence uncertainty.

On the other hand, when a product is perceived to be more complex (e.g., 3D printer), funders' concern about seller's competence to deliver the product is likely to increase. Many products offered on crowdfunding platforms are unique. If a product is also complex, then fewer individuals are likely to possess the necessary capability to produce it compared to one that is simple. Thus, in the absence of any credentialing information on a seller's capabilities, uncertainty about the seller's competence to deliver the product will increase with product complexity, as we hypothesize below.

$H 2 b$ : When product complexity is high, seller competence uncertainty will be greater compared to when product complexity is low.

Since the product creators don't have any prior reputation, there are likely to be concerns about their intentions (e.g., are they trying to make a fast buck?), thereby giving rise to seller opportunism uncertainty. These concerns are likely to become even more acute as product complexity increases. When product complexity is high, challenges to bring the project to fruition are likely to be novel, numerous, and significant, which increase the probability that the creator will be unable to produce the product. Questions about why someone is seeking funding for a project that has a low likelihood of succeeding are likely to go up, increasing the uncertainty about whether the seller is trying to be opportunistic. Therefore, we hypothesize the following:

H2c: When product complexity is high, seller opportunism uncertainty will be greater compared to when product complexity is low.

\subsection{The distinctive influence of different reference groups}

One potential explanation for the negative externalities is the misfit between the information provided by the reference group (crowd) and the information required by the funders. Reference group literature suggests that while adopting social information, individuals use informational reference groups in two distinctive ways [49]. First, individuals actively search for information from people who have expertise when they do not possess the appropriate knowledge to make the decision. Second, individuals make inferences by observing the behaviors of their friends or family members because they deem such significant others as credible information sources.

While individuals can attain reliable information from both groups, the types of information these groups provide are different. To evaluate this, we divided informational reference groups into two based on the nature of information they provide: explicit and implicit informational group. Explicit informational group is one that possesses professional knowledge and has weak-ties to the decision maker [18][27][30], whereas the implicit informational group is one that has interpersonal interaction with and strong-ties to the decision maker. Thus, we expect experts (friends) to be the strongest (weakest) source of explicit information and friends (experts) to be the strongest (weakest) source of implicit information. Thus, we hypothesize that:

H3a: Experts will provide the most explicit information, followed by the crowd, followed by the friends.

H3b: Friends will provide the most implicit information, followed by the crowd, followed by the experts.

We further argue that different types of information provided by these groups reduce different types of uncertainties. Individuals follow their friends' decision to gain implicit information and reduce opportunism uncertainty, similar to trust transference (e.g. I don't know the seller but I trust my friend who trusts the seller, therefore I trust the seller), and they follow experts' decisions to gain explicit information and infer technical information about the product or the seller's capability, whereas the information that the crowd carries, is relatively mixed compared to friends or experts. Therefore, we postulate that:

H4a: When product complexity is high, funders are more likely to base their decision on the experts' choice than on the crowd's choice. 
H4b: When product complexity is high, funders are more likely to base their decision on the crowd's choice over their friends' choice.

H4c: When product complexity is high, funders are more likely to base their decision on the experts' choice over their friends' choice.

H5a: When product complexity is low, funders are more likely to base their decision on the crowd's choice over the experts' choice.

H5b: When product complexity is low, funders are more likely to base their decision on their friends' choice over the crowd's choice.

H5c: When product complexity is low, funders are more likely to base their decision on their friends' choice over the experts' choice.

\section{Method}

We conducted a controlled lab experiment to test our proposed hypotheses. The reason for choosing this method is threefold. First, currently crowdfunding websites do not provide any reference group information. Therefore, to be able to collect the necessary data, we designed several webpages to mimic crowdfunding environment and incorporate influence of different reference groups. Second, the lab experiment allowed us to examine the effects of reference groups at different product complexities. Third, given the explanatory nature of our study, we conducted lab experiments to control potential confounding factors so that we can glean the reference group influence. To ensure generalizability, subjects were recruited through Amazon Mechanical Turk (MTurk), which is considered more demographically diverse and less biased towards a reference group or project compared to students [4][13][49].

The subjects first read brief introductions on the concept of crowdfunding and crowdfunding platforms. Then they read descriptions of two projects and saw pictures of associated high and low complexity products. They were told that they do not know the project initiators and they equally like both products. Subjects were also informed about the value of the product and were told that they will receive a "Thank You" card if a project is successfully funded and finished. In order to minimize the development of preference for any particular product, subjects were not told that they will receive the product. Afterwards, in both high and low complexity product scenarios, subjects answered a short survey about perceived seller uncertainty and their decision to pledge their funds. The scenarios were presented in a random order. To control for the potential impact of different ratios between reference groups, we used ratios which resemble a real world setting: 10 experts vs. 20 friends and 20 experts or friends vs. crowd of 100.

Before the main data collection, we conducted a pilot study to validate the high and low complexity projects, and ensure that subjects are equally interested in both projects. Manipulation of product complexity was based on previous research on task complexity, which suggests that products with more experiential features usually are perceived to be more complex [39]. Three high complexity and three low complexity projects were selected from real crowdfunding platforms. 83 subjects were recruited for the pilot study. Based on subjects' ratings on product complexity and interest, we picked one product from each complexity group: 3D printers as high complex product (mean $=5.27 / 7$ ) and photo albums as low complex projects $($ mean $=3.46 / 7)$. The t-test indicated that perceived project complexity was significantly different $(p<.001)$.

Measurements used in this study were adapted from previous research. Seller uncertainty was measured using scales for seller competence uncertainty (SCP) [32][50] and seller opportunism uncertainty (SOP) [23][50]. Project complexity was rated by subjects after they read the project descriptions. To operationalize the social information perceived from a reference group, a formative construct was created using scales for: 1) explicit information which measures the extent to which funders perceive expertise from a particular reference group to enhance the knowledge about the product; 2) implicit information which measures the extent to which funders can rely on the particular reference group to reduce the concern about project creator's dishonest behaviors. Finally, subjects' actual pledging decisions were measured by examining which product subjects indicated they would pledge their funds to. All constructs were validated in the measurement model using Partial Least Square (PLS), and indicated good convergent and discriminant validity.

\section{Results}

A sample of 326 subjects was recruited from MTurk. 19 failed the attention check, resulting in a final sample of 307. Within these 307 subjects, 163 (53.1\%) were male, and 144 (46.9\%) were female. In general, subjects reported that they are satisfied with social media platforms (e.g. Facebook) $(\mu=5.21 / 7)$ and online transactions (e.g. online payment, ecommerce $)(\mu=5.92 / 7)$. Most of the subjects are relatively familiar with crowdfunding platform such as 
Kickstarter $(\mu=4.74 / 7)$. Consistent with the pilot studies, results of the $t$-test showed that there was significant difference $(\mathrm{p}<.001)$ in perceived complexity between creating a photo album $(\mu=$ $2.98 / 7)$ and building a 3D printer $(\mu=5.43 / 7)$. The main effects proposed in Hypotheses $1 \mathrm{a}$ and $1 \mathrm{~b}$ were tested in six separate path models using PLS; three under high complexity and three under low complexity scenario. Each model consists of social information gained from a particular reference group (modeled as a formative construct arising from explicit and implicit information scales for that particular reference group) leading to two types of seller uncertainty (SOP \& $\mathrm{SCP}$ ). Table 1 shows the path coefficients from social information of each reference group to SOP or SCP under different product complexity scenarios. According to the results, the social information provided by each single reference groups reduced funders' perceived SCP and SOP in both high and low complexity scenarios. Therefore, $\mathrm{H} 1 \mathrm{a}$ and $\mathrm{H} 1 \mathrm{~b}$ are supported. For H2a, we compared the perceived SOP and SCP in each scenario using $t$-tests. Under low product complexity, perceived SOP was higher than $\operatorname{SCP}\left(\mu_{\text {sop }}=4.38\right.$ vs. $\left.\mu_{\text {scp }}=3.66, p<.05\right)$. Thus, H2a is supported. Next, we conducted $t$-test to compare SOP and SCP across scenarios. Both SOP $\left(\mu_{\text {low }}=4.50\right.$ vs. $\left.\mu_{\text {high }}=5.08 ; p<.05\right)$ and SCP $\left(\mu_{\text {low }}=3.66\right.$ vs. $\mu_{\text {high }}=$ $4.61 ; p<.05)$ increase when project complexity increases, thus $\mathrm{H} 2 \mathrm{~b}$ and $\mathrm{H} 2 \mathrm{c}$ are supported.

Table 1. Effect of reference group information on seller uncertainty

\begin{tabular}{|l|c|c|}
\hline \multicolumn{3}{|c|}{ Low Complexity } \\
\hline Reference Group & SOP & SCP \\
\hline Experts & -0.099 & -0.119 \\
\hline Crowd & -0.116 & -0.129 \\
\hline Friends High Complexity \\
\hline \multicolumn{2}{|c|}{-0.131} \\
\hline Reference Group & SOP & SCP \\
\hline Experts & -0.105 & -0.145 \\
\hline Crowd & -0.225 & -0.203 \\
\hline Friends & -0.259 & -0.238 \\
\hline
\end{tabular}

Note: All effects are significant at $p<.05$.

Next, we compared the perceived explicit vs. implicit information from each reference group (H3). Our results indicated that subjects perceived the most explicit information from experts, and least from crowd $\left(\mu_{\text {experts_exp }}=6.21\right.$ vs. $\left.\mu_{\text {crowd_exp }}=3.88 ; p<.01\right)$, with friends in middle $\left(\mu_{\text {friends_exp }}=4.19\right.$ ); for the implicit information, subjects perceived the most from friends, and least from experts $\left(\mu_{\text {friends_imp }}=4.77 \mathrm{vs}\right.$. $\mu_{\text {experts_imp }}=4.18 ; p<.01$ ), and crowd are in middle $\left(\mu_{\text {crowd_imp }}=4.51\right)$, but is indistinguishable from friends
( $p=0.06)$. Therefore, $\mathrm{H} 3 \mathrm{a}$ and $\mathrm{H} 3 \mathrm{~b}$ are partially supported. Finally, we conducted several $t$-tests to examine which reference group funders followed when making pledging decisions in both scenarios ( $\mathrm{H} 4$ \& H5). Decisions are measured as a categorical variable. For example, when comparing crowd to friends in low complexity scenario, the choice of crowd is labeled as 1 and that of friends is labeled as 2. Under high product complexity, funders followed Experts $>$ Crowd $>$ Friends, and under low product complexity funders followed Friends > Experts > Crowd (Table 2). Results provide support for H4a, $\mathrm{H} 4 \mathrm{~b}, \mathrm{H} 4 \mathrm{c}, \mathrm{H} 5 \mathrm{~b}$ and H5c, but not for H5a (crowd over experts in low product complexity).

Table 2. Results of pledging decisions

\begin{tabular}{|c|c|c|}
\hline \multirow[b]{2}{*}{ Comparison } & \multicolumn{2}{|c|}{ Reference Group Followed } \\
\hline & $\begin{array}{c}\text { Low } \\
\text { Complexity }\end{array}$ & $\begin{array}{c}\text { High } \\
\text { Complexity }\end{array}$ \\
\hline C vs. F & $\mathrm{F}$ & $\mathrm{C}$ \\
\hline C vs. E & $\mathrm{E}$ & $\mathrm{E}$ \\
\hline F vs. E & $\mathrm{F}$ & $\mathrm{E}$ \\
\hline
\end{tabular}

\section{Discussion}

We examined the effect of reference groups on seller uncertainty and funder's choice of reference group under different levels of product complexity in a patronage crowdfunding environment. Our analyses showed that social information from reference groups reduced the uncertainty faced by funders. By proposing two different types of social information (implicit vs. explicit), we were able to identify the type of social information each reference group provided during decision-making process. We found that under low product complexity, when funders need more implicit information, they followed friends over experts and crowd to make pledging decisions. On the other hand, under high product complexity, when people need more explicit information, they rationalized their pledging behaviors by following experts over crowd and friends. The results also showed that when funders evaluate low complexity products, they were more concerned about sellers' opportunistic behaviors than sellers' capability to deliver a good quality product, parallel to our expectations. For high complexity products, while both uncertainties increased, uncertainty about seller's competence increased more. This is probably because product complexity corresponds more directly to seller competence uncertainty and the effect on seller opportunism is likely to occur indirectly via seller competence uncertainty. 
Our study has several implications. First, we identified the mechanism by which people follow a particular reference group. According to our results, product complexity dictated the type of information needed by decision makers, which influenced the reference group followed. Second, previous research on informational reference groups focused on the amount of information [4] rather than types of information that these reference groups may provide. We divided the reference groups into explicit informational group providing expertise based information and implicit informational group providing trust based information. We showed that experts provided more explicit information than crowd/friends, and friends provided more implicit information than crowd/experts. The mixed (implicit/explicit) information provided by the crowd may be the reason why the herd behavior results in negative externalities in crowdfunding. This can be avoided if individuals use the more specific information provided by experts and friends. Third, compared to previous research that mainly focuses on seller's ethical characteristics [23][50], we introduced seller competence uncertainty as a new type of seller uncertainty that may exist in online environments. Although different types of seller uncertainties have been investigated in the literature, these studies are mostly in the context of e-business where the products are finished and sellers are generally well-established, in which case seller competence does not play a significant role. As a comparison, in patronage crowdfunding, sellers' competence of delivering satisfactory products is indeed a major concern. This uncertainty can be reduced by referring to the correct informational reference group. Furthermore, we showed that the magnitude of funders' perceived seller uncertainty is a function of product complexity.

The results also have practical implications. The urgent issue faced by all crowdfunding platforms is that there are many "unqualified" projects. Funders do not have access to the necessary information to make rational decisions due to lack of supervision of ongoing projects, and there are low barriers to entry for project initiators. Due to these issues, investors have already had negative perceptions of crowdfunding. This negative attitude could further hurt crowdfunding platforms since the revenue model of these websites depends on the projects that are successfully funded. Our findings may guide the design of crowdfunding platforms. For instance, crowdfunding websites can enforce administrative mechanisms for supervision to filter out unqualified projects. Alternatively, they can integrate social information such as decisions of experts and one's friends to assist decision making. As funders become more satisfied with their choices, they will reinvest on the platform, thereby benefitting the platform.

Although we accounted for extensive aspects of study design and conceptualization, our study also has limitations. First, our study was conducted predominantly in one type of culture. It would be constructive to test the same model in different cultures [24]. Second, in addition to informational influence, friends and experts can also exert normative influence. Future research should also include normative influence to better capture the relationship of seller uncertainty to reference groups. Third, we used two similar products that funders have equal interest to be able to capture the effect of the reference groups. However, on crowdfunding websites, funders show varying interest to multitude of different products. Studying the effect of funders' interest can be a valuable venue for future research.

\section{Conclusions}

Our research provides new insights on the usefulness of different reference groups on crowdfunding platforms. As a consequence of constant use of Internet and social media, social decision making has become a significant part of our everyday decisions. People not only adopt others' ideas or decisions, they are also exerting influence on others. For tasks as simple as evaluating a restaurant, a tourism destination, or purchasing grocery, or as sophisticated as choosing education or career, we are always seeking for information and observing what other people have done. By examining the influence of the informational reference groups with respect to seller uncertainty and product complexity, this research provides insights into how funders decide to pledge and how we can use these insights to improve the design of crowdfunding platforms.

\section{References}

[1] A. Agrawal, C. Catalini, and A. Goldfarb, Offline Relationships, Distance, and the Internet: The Geography of Crowdfunding, NBER, Cambridge, MA, 2011.

[2] T. H. Allison, B. C. Davis, J. C. Short, and J. W. Webb. "Crowdfunding in a Prosocial Microlending Environment: Examining the Role of Intrinsic versus Extrinsic Cues", Entrepreneurship Theory \& Practice (39)1, 2015, pp. 53-73. 
[3] A.V. Banerjee, "A Simple Model of Herd Behavior," The Quarterly Journal of Economics (107) 3, 1992, pp. 797 817.

[4] O.W. Bearden, and M.J. Etzel, "Reference Group Influence on Product and Brand Purchase Decisions", Journal of Consumer Research (9) 2, 1982, pp. 183-194.

[5] L.A. Bebchuk, and J.M. Fried, Pay without Performance: The Unfulfilled Promise of Executive Compensation, MA: Harvard Uni. Press, Cambridge, 2006.

[6] G.S. Becker, The Economic Approach to Human Behavior, IL: University of Chicago Press, Chicago, 1976.

[7] P. Belleflamme, T. Lambert, and A. Schwienbacher, "Crowdfunding: An Industrial Organization Perspective," Working Paper, Universite Catholique de Louvain, 2010.

[8] A. J. Berinsky, G. A. Huber, and G.S. Lenz, "Evaluating Online Labor Markets for Experimental Research: Amazon.com's Mechanical Turk", Political Analysis, (20) 3, 2012, pp. 351-368.

[9] E. Berkovich, "Search and Herding Effects in Peer-toPeer Lending: Evidence from Prosper.com", Annals of Finance (7) 3, 2011, pp. $389-405$.

[10] S. Bikhchandani, D. Hirshleifer, and I. Welch, "Learning from the Behavior of Others: Conformity, Fads, and Informational Cascades", Journal of Economic Perspectives (12) 3, 1998, pp. 151-170.

[11] Bloomberg.com, http://www.bloomberg.com/news/ articles /2014-04-18/how-to-get-funded-on-kickstarter.

[12] U. Bretschneider, K. Knaub, and E. Wieck, "Motivations for Crowdfunding: What Drives the Crowd to Invest in Start-Ups?", in Proceedings of the 22nd European Conference on Information Systems, Tel Aviv, Israel, 2014.

[13] M. Buhrmester, T. Kwang, and S.D. Gosling, "Amazon's Mechanical Turk A New Source of Inexpensive, Yet High-quality, Data?", Perspectives on Psychological Science (6) 1, 2011, pp. 3-5.

[14] R.S. Burt, "Social Contagion and Innovation: Cohesion versus Structural Equivalence", American Journal of Sociology (92) 6, 1987, pp. 1287-1335.

[15] G. Burtch, "Herding Behavior as a Network Externality", in Proceedings of the 32nd International Conference on Information Systems, Shanghai, China, 2011.

[16] G. Burtch, A. Ghose, and S. Wattal, "An Empirical Examination of the Antecedents and Consequences of Contribution Patterns in Crowd-Funded Markets", Information Systems Research (24) 3, 2013, pp. 499-519.
[17] G. Burtch, A. Ghose, and S. Wattal, "Cultural Differences and Geography as Determinants of online Prosocial Lending”, MIS Quarterly (38) 3, 2014, pp. 773-794.

[18] T.L. Childers, and A.R. Rao, "The Influence of Familial and Peer-Based Reference Groups on Consumer Decisions", Journal of Consumer Research (19) 2, 1992, pp. 198-211.

[19] M.S. Cohen, “A Database Tool to Support Probabilistic Assumption-Based Reasoning in Intelligence Analysis", in Proceedings of the 1989 Joint Director of the C2 Symposium, 1989, pp. 27-29.

[20] M. G. Colombo, C. Franzoni, and C. Rossi-Lamastra, "Internal Social Capital and the Attraction of Early Contributions in Crowdfunding", Entrepreneurship Theory and Practice, (39) 1, 2015, pp. 75-100.

[21] R.H. Day, "Rationality, Entrepreneurship and Institutional Evolution”, Revue Economique (46) 6, 1995, pp. 1473-1485.

[22] R.M. Dawes, Rational Choice in an Uncertain World. New Implications for Future Army Leaders. in J. G. Hunt and J. Blair York: Harcourt Brace Jovanovich, 1988.

[23] A. Dimoka, Y. Hong, and P.A. Pavlou, "On Product Uncertainty in Online Markets: Theory and Evidence", MIS Quarterly (36) 2, 2012, pp. 395-426.

[24] P.M. Doney, J.P. Cannon, and M.R. Mullen, "Understanding the Influence of National Culture on the Development of Trust", Academy of Management Review, (23) 3, 1998, pp. 601-620.

[25] H.J. Einhorn, and R.M. Hogarth, "Decision Making under Ambiguity", Journal of Business, (59) 4, 1986, pp. $225-250$.

[26] B.G. Englis, and M.R. Solomon, "To Be and Not To Be: Lifestyle Imagery, Reference Groups, and the Clustering of America", Journal of Advertising (24) 1, 1995, pp. 13-28.

[27] J.E. Escalas, and J.R. Bettman, "You Are What They Eat: The Influence of Reference Groups on Consumers' Connections to Brands", Journal of Consumer Psychology (13) 3, 2003, pp. 339-348.

[28] J. Feller, R. Gleasure, and S. Treacy, "From the Wisdom to the Wealth of Crowds: A Metatriangulation of Crowdfunding Research,” TOTO Research Project, 2013.

[29] L. Festinger, 1954. "A Theory of Social Comparison Processes”, Human Relations (7) 2, 1954, pp. 117-140.

[30] V.S. Folkes, and T. Kiesler, Social Cognition: Consumer Inferences about the Self and Others, in Handbook of Consumer Behavior, T. S Robertson \& H. H. 
Kassarjian (eds.), NJ: Prentice Hall, Englewood Cliffs, 1991, pp. 281-315.

[31] Kickstarter.com, https://www.kickstarter.com/

[32] D. Gefen, E. Karahanna, and D.W. Straub, "Trust and TAM in online Shopping: An Integrated Model", MIS Quarterly (27) 1, 2003, pp. 51-90.

[33] E.M. Gerber, J.S. Hui, and P.Y. Kuo, "Crowdfunding: Why People Are Motivated to Post and Fund Projects on Crowdfunding Platforms," Northwestern University Creative Action Lab, Evanston, 2012.

[34] T. Goerzen, and D. Kundisch, "Can the Crowd Substitute Experts in Evaluation of Creative Ideas? An Experimental Study Using Business Models", in Proceedings of the 22nd Americas Conference on Information Systems ( AMCIS), San Diego, 2016.

[35] A. Heath, Rational Choice and Social Exchange: A Critique of Exchange Theory, UK: Cambridge University Press, Cambridge, 1976

[36] M. Herzenstein, U.M. Dholakia, and R.L. Andrews, "Strategic Herding Behavior in Peer-to-Peer Loan Auctions", Journal of Interactive Marketing (25) 1, 2011, pp. 27-36.

[37] E. Hirst, and M. Schweitzer, "Electric-Utility Resource Planning and Decision-Making: The Importance of Uncertainty”, Risk Analysis (10) 1, 1990, pp. 137-146.

[38] E. Á. Horvát, J. Uparna, and B. Uzzi, "Network vs Market Relations: The Effect of Friends in Crowdfunding", in Proceedings of the 2015 IEEE/ACM International Conference on Advances in Social Networks Analysis and Mining 2015, ACM, 2015, pp. 226-233.

[39] Z. Jiang, and I. Benbasat, "The Effects of Presentation Formats and Task Complexity on Online Consumers' Product Understanding”, MIS Quarterly (31) 3, 2007, pp. 475-500.

[40] D. Kahneman, and A. Tversky, "Prospect Theory: An Analysis of Decision under Risk", Econometrica: Journal of the Econometric Society, (47) 2, 1979, pp. 263-291.

[41] M. Kilduff, "The Interpersonal Structure of Decision Making: A Social Comparison Approach to Organizational Choice," Organizational Behavior and Human Decision Processes, (47) 2, 1990, pp. 270-288.

[42] K. Kim, and S. Viswanathan, "The Experts in the Crowd: The Role of Reputable Investors in a Crowdfunding Market”, TPRC, August 2014.

[43] N. Kock, "The Psychobiological Model: Towards a New Theory of Computer-Mediated Communication Based on Darwinian Evolution", Organization Science (15) 3, 2004, pp. 327-348.

[44] V. Kuppuswamy, and B.L. Bayus, "Crowdfunding Creative Ideas: The Dynamics of Projects Backers in Kickstarter", SSRN Working Paper, http://papers.ssrn.com /sol3/papers.cfm?abstract id=2234765, 2013.

[45] M. Lin, and S. Viswanathan, 2015. "Home Bias in Online Investments: An Empirical Study of an Online Crowdfunding Market", Management Science, Sep 2, 2015, pp. 1393-1414.

[46] S. Lindenberg, Social Rationality versus Rational Egoism, in Handbook of Sociological Theory, J. H. Turner (eds.), New York: Springer, New York, 2001, pp. 635-668.

[47] R. Lipshitz, and O. Strauss, "Coping with Uncertainty: A Naturalistic Decision-Making Analysis", Organizational Behavior and Human Decision Processes, (69) 2, 1997, pp. 149-163.

[48] E. Mollick, The Dynamics of Crowdfunding: An Exploratory Study", Journal of Business Venturing, (29) 1, 2014, pp. 1-16.

[49] C.W. Park, and V.P. Lessig, "Differences in Susceptibility to Reference Group Influence", Journal of Consumer Research (4) 2, 1977, pp. 102-110.

[50] P.A. Pavlou, H. Liang, and Y. Xue, "Understanding and Mitigating Uncertainty in Online Exchange Relationships: A Principal-Agent Perspective", MIS Quarterly (31) 1, 2006, pp. 105-136.

[51] D.S. Scharfstein, and J.C. Stein, "Herd Behavior and Investment", American Economic Review (80) 3, 1990, pp. 465-479.

[52] A. Schwienbacher, and B. Larralde, Crowdfunding of Small Entrepreneurial Ventures. Handbook of Entrepreneurial Finance, Oxford Uni. Press, Oxford, 2010.

[53] J.F. Scott, Rational Choice Theory. In Understanding Contemporary Society: Theories of the Present, Abigail Halcli, Gary Browning, and Frank Webster (Ed.), Sage, London, 2000, pp. 126-138.

[54] The Register, http://www.theregister.co.uk/ 2014/06/24/ifind kickstarter/

[55] C. Ward, and V. Ramachandran, "Crowdfunding the Next Hit: Microfunding Online Experience Goods", In Workshop on Computational Social Science and the Wisdom of Crowds at NIPS 2010.

[56] J. Zhang, and P. Liu, "Rational Herding in Microloan Markets”, Management Science (58) 5, 2012, pp. 892-912. 